\title{
Correction: Strategies for the Successful Implementation of a Novel iPhone Loaner System (iShare) in mHealth Interventions: Prospective Study
}

William E Yang ${ }^{1}$, MD; Erin M Spaulding ${ }^{2}$, RN, BSN; David Lumelsky ${ }^{3}$, BS; George Hung ${ }^{1}$, MD; Pauline Phuong Huynh $^{1}$, BA; Kellen Knowles ${ }^{1}$, MD; Francoise A Marvel ${ }^{1,4}$, MD; Valerie Vilarino ${ }^{3}$, BA; Jane Wang ${ }^{1}$, MD; Lochan M Shah ${ }^{1}$, BA; Helen Xun ${ }^{1}$, BS; Rongzi Shan ${ }^{4}$, BS; Shannon Wongvibulsin ${ }^{1,5}$, PhD; Seth S Martin ${ }^{1,4}$, MD, MHS

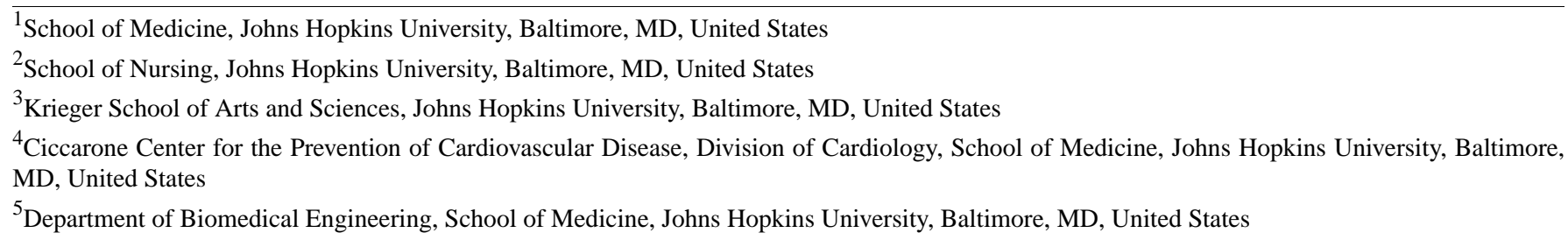

\section{Corresponding Author:}

William E Yang, MD

School of Medicine

Johns Hopkins University

4940 Eastern Ave

Baltimore, MD, 21224

United States

Phone: 14105500100

Email: wyang@jhmi.edu

\section{Related Article:}

Correction of: https://mhealth.jmir.org/2019/12/e16391/

(JMIR Mhealth Uhealth 2021;9(9):e31472) doi: $10.2196 / 31472$

In "Strategies for the Successful Implementation of a Novel iPhone Loaner System (iShare) in mHealth Interventions: Prospective Study" (JMIR Mhealth Uhealth 2019;7(12):e16391) the authors noted two errors.

In the Results section of the originally published paper, the first paragraph of the subsection "Evaluation of Process Outcomes" included incorrect numerators and denominators in the statistical values introduced during the copyediting process. The final two sentences of this paragraph were originally published as follows:

Compared to iPhone owners, iShare participants were slightly younger (age range 30-81 years, mean 57.4 [SD 11] vs age range 32-89 years, mean 60.8 [SD 11]). They were also more likely to be women $(72 / 200$, $36.0 \%$ vs $45 / 200,23.0 \%)$, of black race $(50 / 200$, $25.0 \%$ vs 28/200, $14.0 \%)$, and insured by Medicaid (40/200, 20.0\% vs 8/200, 4.0\%).

This has been corrected to:
Compared to iPhone owners, iShare participants were slightly younger (age range 30-81 years, mean 57.4 [SD 11] vs age range 32-89 years, mean 60.8 [SD 11]). They were also more likely to be women (33/92, $35.9 \%$ vs 25/108, 23.2\%), of black race (23/92, $25.0 \%$ vs 15/108, 13.9\%), and insured by Medicaid (18/92, $19.6 \%$ vs $4 / 108,3.7 \%$ ).

As well, the phone number of the Corresponding Author has been updated from the originally published number to " 1410 550 0100."

The correction will appear in the online version of the paper on the JMIR Publications website on September 20, 2021, together with the publication of this correction notice. Because this was made after submission to PubMed, PubMed Central, and other full-text repositories, the corrected article has also been resubmitted to those repositories. 
This is a non-peer-reviewed article. Submitted 22.06.21; accepted 24.06.21; published 20.09.21.

Please cite as:

Yang WE, Spaulding EM, Lumelsky D, Hung G, Huynh PP, Knowles K, Marvel FA, Vilarino V, Wang J, Shah LM, Xun H, Shan R, Wongvibulsin S, Martin SS

Correction: Strategies for the Successful Implementation of a Novel iPhone Loaner System (iShare) in mHealth Interventions: Prospective Study

JMIR Mhealth Uhealth 2021;9(9):e31472

URL: https://mhealth.jmir.org/2021/9/e31472

doi: $\underline{10.2196 / 31472}$

PMID:

(CWilliam E Yang, Erin M Spaulding, David Lumelsky, George Hung, Pauline Phuong Huynh, Kellen Knowles, Francoise A Marvel, Valerie Vilarino, Jane Wang, Lochan M Shah, Helen Xun, Rongzi Shan, Shannon Wongvibulsin, Seth S Martin. Originally published in JMIR mHealth and uHealth (https://mhealth.jmir.org), 20.09.2021. This is an open-access article distributed under the terms of the Creative Commons Attribution License (https://creativecommons.org/licenses/by/4.0/), which permits unrestricted use, distribution, and reproduction in any medium, provided the original work, first published in JMIR mHealth and uHealth, is properly cited. The complete bibliographic information, a link to the original publication on https://mhealth.jmir.org/, as well as this copyright and license information must be included. 